\title{
Coping with Cancer in Patients with Head and Neck Cancers in Iran
}

\section{Fatemeh Moslemi ${ }^{1}$, Nazanin Rahbanian' ${ }^{2}$, Elham Abbaszadeh ${ }^{3}$, Behjat Kalantari ${ }^{4}$ and Maryam Alsadat Hashemipour ${ }^{5 *}$}

${ }^{1}$ Postgraduate Student of Pediatric Dentistry, Department of Pediatric Dentistry,

Dental School, Kerman of University of Medical Sciences, Kerman, Iran

${ }^{2}$ General Dentist, Private Practice, Kerman, Iran

${ }^{3}$ Assistant Professor of Oral Medicine, Department of Oral Medicine, Dental School,

Kerman of University of Medical Sciences, Kerman, Iran

${ }^{4}$ Assistant Professor of Oncology, Department of Oncology, Medical School, Kerman

of University of Medical Sciences, Kerman, Iran

${ }^{5}$ Professor of Oral Medicine, Department of Oral Medicine, Dental School, Kerman

of University of Medical Sciences, Kerman, Iran

*Corresponding Author: Maryam Alsadat Hashemipour, Professor of Oral Medicine,

Department of Oral Medicine, Dental School, Kerman of University of Medical

Sciences, Kerman, Iran.
Received: April 15, 2021

Published: May 24, 2021

(C) All rights are reserved by Maryam Alsadat Hashemipour., et al.

\begin{abstract}
Introduction: Many people, having been diagnosed with cancer, experience high levels of inability and frustration while coping with this disease in individual and familial lives. To return to their normal lives, these patients need help to cope with the disease and meet their various needs. Coping with cancer refers to a set of attitudes and practices that one adopts to preserve health, well-being, happiness, and to overcome the stresses from cancer. This study aimed to investigate coping with cancer in patients with head and neck cancers in Kerman and Isfahan using the Cancer Coping Questionnaire.

Materials and Methods: The studied population was patients presenting to the Oncology Ward of Shafa and Bahonar Hospitals in Kerman and Omid Hospital in Isfahan in 2019 - 2020. The questionnaire was provided by a senior student to the patients in a quiet environment. A questionnaire consisting of several parts was used to collect data. The demographic questionnaire included age, type of treatment, stage of illness, marital status, level of education, economic status and lifestyle. The Cancer Coping Questionnaire consists of 22 items with two subscales of personal and interpersonal. In this study, descriptive statistics, i.e., percentage and frequency, mean and standard deviation, t-tests, ANOVA and SPSS21 statistical software was applied.

Results: 164 people participated in this study, 85 were men and 79 were women. The mean age of the participants was $40.3 \pm 5.12$ years. The mean coping score by participants was $37.99 \pm 12.2$. Considering that this variable can range from 22 to 88 , one would conclude that the coping rate of the people with head and neck cancer was at a low level. The study of the relationship between age, coping and disease duration suggested that there was no significant relationship between age and coping level $(\mathrm{P}=0.662)$.

Also, there was no significant relationship between the duration of the disease and the mean score from the questionnaire $(\mathrm{P}=$ 0.156). The coping of people undergoing chemotherapy was greater than that in surgery $(P=0.024)$, but it was no different from surgery with chemotherapy $(\mathrm{P}=0.442)$.

The results suggested that there was no significant relationship between coping, gender, marital status and level of education $(\mathrm{P}=$ $0.901, \mathrm{P}=0.494, \mathrm{P}=0.275, \mathrm{P}=0.556$, respectively).

Conclusion: This study reaffirmed that coping in people with head and neck cancer was generally low. Also, a low average score was obtained in the personal and interpersonal dimensions. Individuals' incomes may create differences in the extent of their coping, as increasing age reduces planning and deviated thinking in individuals. To sum, as the duration of the disease increases, the amount of coping increases.

Keywords: Coping; Cancer; Patients; Head; Neck
\end{abstract}




\section{Introduction}

Head and neck cancers are the sixth most common cancers in the human body. The prevalence of head and neck cancers is reported to be between 5 and $50 \%$ across the world, with South Asia and Southern Europe having the highest prevalence rates [1].

In the meantime, head and neck cancers are mostly prevalent in such countries as France, Brazil, India and South America [2]. Approximately 36,500 new cases are reported each year, as 11,000 people die from cancer in the United States alone [2]. In Australia, the prevalence of this cancer amounts to 12.3 and is seen as the fifth most common cancer $[3,4]$.

Nasopharyngeal carcinoma, forming the major tumor of the nose and throat areas, is less prevalent in the United States, but more prevalent in the Chinese population. Nasal cavity and paranasal sinuses cancers account for $2 \%$ of the newly diagnosed cancers. Included in the pharyngeal cancers is the supraglottis cancer making up about $95 \%$ of pharyngeal cancers $[5,6]$. In general, when speaking head and neck cancers, it is meant the upper digestive and respiratory tract including the paranasal sinuses, nasal cavity, oral pharyngeal, oral cavity, hypopharynx, larynx, esophagus, and cervical region. The most common carcinoma in this area is squamous epithelial cell carcinoma [7].

Head and neck carcinomas, such as skin cancers and intracranial tumors account for $5 \%$ of all cancers in men and $2 \%$ of all cancers in women [7].

The age of development of this type of cancer is usually around 60 to 70. Eighty percent of SCC tumors and another 20 percent include such rare cancers as the salivary glands, thyroid, and sarcomas [7].

Smoking is an important cause of cancer. Alcohol consumption directly affects the epithelial cells of the oral mucosa, increasing its permeability, while at the same time causing dehydration. There is some evidence suggesting the direct effect of alcohol on genes. Dysfunctional uptake of nutrients, P53, vitamins, and impaired liver function are other carcinogens produced by alcohol [7].

Head and neck cancers are treated differently depending on the cancer stage. For some reasons, most patients with head and neck cancer experience delayed examinations, which makes treatment difficult. Treatment options include a combination of surgery, radiotherapy and chemotherapy. Palliative care is often key in advanced stages of the disease [8].
Complications of treatment increase pain and discomfort in patients with head and neck cancer. The most common complaints of patients include pain, dry mouth, sticky saliva, nutritional problems and difficulty speaking, among others [9]. Also, organ removal due to extended surgery to control the disease can cause psychological stress and physical pains in patients. Other problems include economic problems, job problems and adverse effects disrupt the family life $[10,11]$.

Many people, having been diagnosed with cancer, experience high levels of inability and frustration while coping with this disease in individual and familial lives [12]. To return to their normal lives, these patients need help to cope with the disease and meet their various needs [13].

Coping with cancer refers to a set of attitudes and practices that one adopts to preserve health, well-being, happiness, and to overcome the stresses from cancer [14].

Those cancer patients who are not resistant to stress get frustrated, become unable to focus on problems, and cannot make the right decisions, they do not have a plan for the right lifestyle, are pessimistic about their lives, have no control over their own destiny, and do not play an active role in how to form their own lives. Their feedback and practical conducts are irrational and are unable to meet the challenges facing their lives. These complications leave such a profound and lasting effect on the patient's psyche that a recollection of bitter memories of the past even after years could cause anxiety for them, affecting their coping abilities [15].

Coping with the stressful event of cancer is a dynamic process. For Lazarus and Folkman, cancer can engender a variety of responses, including two types of problem-oriented and emotionoriented coping styles [16,17].

Problem-oriented coping is indicative of a problem-oriented and purposeful effort to solve the problem, reorganize the problem, or attempt to change the situation. This strategy focuses on engaging with the problem in a systematic and orderly manner. The most important of these strategies include confrontational coping, active efforts to change the present situation, seeking social support, and deliberate efforts to resolve the situation. Emotion-oriented coping refers to self-oriented reactions aimed at reducing stress, rather than solving a rational problem. New reactions include emotional responses. Negative emotion reactions include emotional expressions in the form of isolation, repression and quitting the subject [15]. Since studies conducted in Iran on the prevalence of head and neck cancers suggests an increase in the prevalence of this type of 
cancer [18] and that no study has been conducted in this field in Iran so far, this study aimed to investigate coping with cancer in patients with head and neck cancers in Kerman and Isfahan using the Cancer Coping Questionnaire.

\section{Materials and Methods}

This research was descriptive-analytical. The studied population was patients presenting to the Oncology Ward of Shafa and Bahonar Hospitals in Kerman and Omid Hospital in Isfahan in 2019 - 2020. The cancers studied included all head and neck cancers except for the skin, eye and brain cancers included in the study according to the oncologist examination. Inclusion criteria were going through chemotherapy or surgery, no cancer in other parts of the body, not having any known mental illness and no use of psychiatric drugs. Exclusion criteria were the occurrence of any stressful event for the patient or first-degree members of the patient's family in the past 6 months.

Also, illiterate people were excluded from the study. Before the study began, verbal consent was obtained from all patients and then the Cancer Coping Questionnaire. The questionnaire was provided by a senior student to the patients in a quiet environment. The objective of this study was explained to each person and a questionnaire was provided to them if accepted. In the meantime, all people were assured as to the confidentiality of the information in the questionnaire and the data were examined only from a statistical point of view.

A questionnaire consisting of several parts was used to collect data. The demographic questionnaire included age, type of treatment, stage of illness, marital status, level of education, economic status and lifestyle. The Cancer Coping Questionnaire consists of 22 items with two subscales of personal and interpersonal. Personal subscale is a subset including items 1 to 14 discussing questions pertaining to coping (items $2,6,7,12$ ), positive focus (items 1 , 9,14 ), planning questions (items $5,13,10$ ) and deviated thinking (items 3, 4, 8). Interpersonal subscale items also include questions 15 to 22 . This scale was scored on a 4-point Likert scale, including nothing (score 1), low (2), medium (3) and high (4). The questionnaire scores vary between 22 and 88 . Higher scores indicate greater coping strategies.

In this study, descriptive statistics, i.e. percentage and frequency, mean and standard deviation, t-tests and ANOVA tests to measure the relationship between demographic variables and coping with cancer, as well as Pearson correlation coefficient and stepwise multiple linear regression to measure the relationship between coping with cancer and the stated independent variables were used. For statistical analysis, SPSS21 statistical software was applied. Moreover, this research was registered with an ethics code of IR.KMU. REC.1398.449 at the ethics committee affiliated with the Kerman University of Medical Sciences.

\section{Results}

164 people participated in this study, 85 were men and 79 were women. The mean age of the participants was $40.3 \pm 5.12$ years and $95 \%$ of the participants were between 37 and 43 years old. In terms of income, most of the participants had an income of 80 to 150 dollars, and people with more than 300 dollars held a lower percentage; this is while most of the participants were living with their families. The most common treatment is chemotherapy followed by surgery and then a combination of chemotherapy and surgery (Table 1).

\begin{tabular}{|c|c|c|c|}
\hline \multicolumn{2}{|c|}{ Characteristics } & No. & $\%$ \\
\hline \multirow[t]{2}{*}{ Gender } & Male & 85 & 51.80 \\
\hline & Female & 79 & 48.20 \\
\hline \multirow[t]{2}{*}{ Marriage status } & Single & 60 & 37.50 \\
\hline & Married & 100 & 62.50 \\
\hline \multirow[t]{7}{*}{ Occupation } & Non-academic Student & 16 & 9.80 \\
\hline & Student & 22 & 13.40 \\
\hline & Employee & 38 & 23.20 \\
\hline & Self-employed & 34 & 20.70 \\
\hline & Retired & 22 & 13.40 \\
\hline & housewife & 24 & 17.10 \\
\hline & Unemployed & 4 & 2.40 \\
\hline \multirow[t]{5}{*}{ Education level } & High school & 26 & 16.10 \\
\hline & Diploma & 40 & 24.80 \\
\hline & Associate's & 30 & 18.60 \\
\hline & Bachelor's & 58 & 36.00 \\
\hline & Master's & 7 & 4.30 \\
\hline \multirow[t]{4}{*}{ Average income } & $<80$ dollars & 36 & 23.80 \\
\hline & 80 - 150 dollars & 53 & 35.10 \\
\hline & 150 - 350 dollars & 41 & 27.20 \\
\hline & Over 350 dollars & 21 & 13.90 \\
\hline \multirow{4}{*}{$\begin{array}{l}\text { Living with/with- } \\
\text { out others }\end{array}$} & With his wife & 95 & 59.70 \\
\hline & Together with parents & 31 & 19.50 \\
\hline & With friends & 10 & 6.30 \\
\hline & Single & 23 & 14.50 \\
\hline \multirow[t]{3}{*}{ Type of treatment } & Chemotherapy & 71 & 44.3 \\
\hline & Surgery & 55 & 34.4 \\
\hline & $\begin{array}{l}\text { Chemotherapy and } \\
\text { surgery }\end{array}$ & 34 & 22.3 \\
\hline
\end{tabular}

Table 1: Demographic characteristics of the participants. 
This study suggested that more than half of the patients $(62.3 \%$ - 102 people) with stress and 64.5\% (106 people) had suffered from stress or worried about their diseases during the last week.

Examining the relationship between age and duration of the disease was found to be significant $(0.288)$ using a correlation coefficient. The duration of the disease increases with age $(\mathrm{P}=0.0001)$. This indicates that people with acute forms of the disease die soon. The mean duration of the disease among married people was 16.84 \pm 17.39 which was greater than the duration of the disease among the single people $(10.62 \pm 11.7)(\mathrm{P}=0.019)$. Also, the duration of the disease was the same among the treatments defined in the study $(\mathrm{P}=0.271)$.

The mean coping score by participants was $37.99 \pm 12.2$. Considering that this variable can range from 22 to 88, one would conclude that the coping rate of the people with head and neck cancer was at a low level. The study of the relationship between age, coping and disease duration suggested that there was no significant relationship between age and coping level $(\mathrm{P}=0.662)$ and in other words, increasing or decreasing age was not found to cause patients to be more coping with their disease.

Also, there was no significant relationship between the duration of the disease and the mean score from the questionnaire $(\mathrm{P}$ $=0.156$ ); in other words, increased or decreased duration of the treatment did not create more coping styles in patients. The extent to which cancer patients were coping with the disease was significantly dependent on the type of treatment $(\mathrm{P}=0.032)$. Thus, the coping of people undergoing chemotherapy was greater than that in surgery $(P=0.024)$, but it was no different from surgery with chemotherapy $(\mathrm{P}=0.442)$. The findings indicated that the peoples' coping styles depended on their income $(\mathrm{P}=0.045)$. In other words, the coping of people with incomes under 80 dollars was less than people with incomes between 80 to 150 dollars $(\mathrm{P}=0.033)$ and 150 to 300 dollars $(\mathrm{P}=0.008)$.

The results suggested that there was no significant relationship between coping, gender, marital status and level of education $(\mathrm{P}=$ $0.901, \mathrm{P}=0.494, \mathrm{P}=0.275$, respectively $(\mathrm{P}=0.556$ ) (Table 2 ).

The mean coping score was $23.19 \pm 8.12$ in the personal dimension and $14.09 \pm 3.07$ in the interpersonal dimension. Multivariate analysis of variance suggested that from among the demographic variables, only the income variable made a difference in both individual and non-individual dimensions $(P=0.041)$. Also, the rate

\begin{tabular}{|c|c|c|c|c|}
\hline \multicolumn{2}{|c|}{ Demographic variable } & \multirow{2}{*}{$\begin{array}{l}\text { Mean } \\
37.45\end{array}$} & \multirow{2}{*}{$\frac{\text { SD }}{11.48}$} & \multirow{2}{*}{$\frac{\text { P value }}{0.556}$} \\
\hline Gender & Male & & & \\
\hline & Female & 38.54 & 12.96 & \\
\hline \multirow{2}{*}{$\begin{array}{l}\text { Marriage } \\
\text { status }\end{array}$} & Single & 36.77 & 10.60 & \multirow[t]{2}{*}{0.494} \\
\hline & Married & 38.12 & 12.90 & \\
\hline \multirow[t]{7}{*}{ Occupation } & $\begin{array}{c}\text { Non-academic Stu- } \\
\text { dent }\end{array}$ & 33.00 & 7.01 & \multirow[t]{7}{*}{0.275} \\
\hline & Student & 38.73 & 14.91 & \\
\hline & Employee & 39.87 & 12.84 & \\
\hline & Self-employed & 40.03 & 9.40 & \\
\hline & Retired & 34.45 & 12.11 & \\
\hline & Housewife & 36.14 & 13.61 & \\
\hline & Unemployed & 41.75 & 9.88 & \\
\hline \multirow{5}{*}{$\begin{array}{l}\text { Education } \\
\quad \text { level }\end{array}$} & High school & 3.54 & 14.27 & \multirow{5}{*}{0.901} \\
\hline & Diploma & 35.80 & 9.14 & \\
\hline & Associate's & 39.80 & 12.63 & \\
\hline & Bachelor's & 40.02 & 12.34 & \\
\hline & Master's & 42.71 & 14.38 & \\
\hline \multirow{4}{*}{$\begin{array}{l}\text { Average } \\
\text { income }\end{array}$} & $<80$ dollars & 33.42 & 14.46 & \multirow[t]{4}{*}{0.396} \\
\hline & 80 - 150 dollars & 39.11 & 11.11 & \\
\hline & 150 - 350 dollars & 40.95 & 11.92 & \\
\hline & Over 350 dollars & 36.29 & 11.62 & \\
\hline
\end{tabular}

Table 2: Average coping score in terms of demographic variables.

of interpersonal coping in people with incomes below 350 dollars and above was the same $(\mathrm{P}=0.001)$ and incomes between 80 150 dollars $(\mathrm{P}=0.031)$ and $150-350$ dollars $(\mathrm{P}=0.044)$ showed a different coping style. In terms of individual coping, people with incomes below 80 dollars and between 80-150 dollars were not significantly different from each other $(\mathrm{P}=0.621)$ and those with incomes of 150 to 300 dollars $(P=0.011)$ and 350 dollars and above $(\mathrm{P}=0.031)$ were different. Moreover, the results showed that a rise in age reduced the individual coping $(\mathrm{P}=0.001, \mathrm{~B} 1=$ -0.112) and interpersonal coping ( $\mathrm{P}=0.001, \mathrm{~B} 2=-0.049)$ whereas increased duration of the disease increased individual coping $(\mathrm{P}=$ $0.001, \mathrm{~B} 1=0.161)$ and interpersonal coping $(\mathrm{P}=0.001, \mathrm{~B} 2=0.150)$ (Table 3).

Examining the relationship between the subscales of coping, positive focus, planning and deviated thinking with other variables, it was concluded that people's income had made a difference in the level of coping. The level of coping between people with income levels below 80 dollars and above 350 dollars was not significantly 


\begin{tabular}{|c|c|c|c|c|c|c|}
\hline \multirow{2}{*}{\multicolumn{2}{|c|}{ Demographic variable }} & \multicolumn{2}{|c|}{ Personal } & \multicolumn{2}{|c|}{ Interpersonal } & \multirow{4}{*}{$\begin{array}{c}\text { P-value } \\
0.947\end{array}$} \\
\hline & & \multirow{2}{*}{$\begin{array}{l}\text { Mean } \\
23.96 \\
\end{array}$} & \multirow{2}{*}{$\begin{array}{c}\text { SD } \\
9.03\end{array}$} & \multirow{2}{*}{$\begin{array}{l}\text { Mean } \\
13.58 \\
\end{array}$} & \multirow{2}{*}{$\begin{array}{c}\text { SD } \\
6.55 \\
\end{array}$} & \\
\hline Gender & Male & & & & & \\
\hline & Female & 24.25 & 7.05 & 14.00 & 5.16 & \\
\hline \multirow[t]{2}{*}{ Marriage status } & Single & 24.92 & 8.86 & 14.10 & 5.66 & \multirow[b]{2}{*}{0.837} \\
\hline & Married & 24.14 & 7.66 & 13.85 & 5.76 & \\
\hline \multirow[t]{7}{*}{ Occupation } & Non-academic Student & 23.13 & 9.33 & 10.75 & 5.20 & \multirow[t]{7}{*}{0.683} \\
\hline & Student & 25.86 & 7.58 & 13.86 & 5.90 & \\
\hline & Employee & 25.37 & 8.34 & 15.29 & 5.85 & \\
\hline & Self-employed & 24.09 & 8.40 & 14.03 & 6.22 & \\
\hline & Retired & 22.73 & 9.67 & 12.36 & 6.75 & \\
\hline & Housewife & 24.29 & 6.12 & 14.61 & 5.10 & \\
\hline & Unemployed & 17.50 & 5.00 & 12.75 & 3.59 & \\
\hline \multirow[t]{5}{*}{ Education level } & High school & 23.88 & 8.14 & 15.15 & 7.73 & \multirow[t]{5}{*}{0.795} \\
\hline & Diploma & 24.20 & 8.86 & 13.10 & 5.66 & \\
\hline & Associate's & 25.20 & 7.46 & 13.40 & 5.54 & \\
\hline & Bachelor's & 24.60 & 7.96 & 14.40 & 5.35 & \\
\hline & Master's & 22.57 & 9.68 & 11.57 & 5.88 & \\
\hline \multirow[t]{4}{*}{ Average income } & $<80$ dollars & 23.61 & 7.63 & 13.08 & 6.15 & \multirow[t]{4}{*}{$* 0.041$} \\
\hline & 80 - 150 dollars & 22.91 & 8.34 & 14.45 & 6.51 & \\
\hline & 150 - 350 dollars & 25.80 & 7.05 & 14.68 & 5.00 & \\
\hline & Over 350 dollars & 25.00 & 11.21 & 11.81 & 6.52 & \\
\hline \multirow[t]{3}{*}{ Type of treatment } & Chemotherapy & 23.63 & 8.23 & 14.28 & 6.24 & \multirow[t]{3}{*}{0.123} \\
\hline & Surgery & 25.09 & 8.24 & 14.11 & 5.73 & \\
\hline & Chemotherapy and surgery & 23.97 & 8.49 & 12.74 & 5.61 & \\
\hline
\end{tabular}

Table 3: Relationship between demographic variables and duration and type of treatment with personal and interpersonal scales.

$$
\text { *: } \mathrm{P}<0.05 \text { is significant. }
$$

different from each other $(\mathrm{P}=0.921)$ but was different with those having a level of income between 80150 dollars $(\mathrm{P}=0.007)$ and above 150 dollars $(P=0.001)$. The results also suggested that a rise in age reduced planning $(\mathrm{P}=0.011, \mathrm{~B} 1=-0.139)$ and deviated thinking $(\mathrm{P}=0.009, \mathrm{~B} 2=-0.147)$ in people. However, as the duration of the disease increased, the rate of coping increased also $(\mathrm{P}=$ 0.072 , B1 $=0.145$ ) (Table 4).

\section{Discussion}

Head and neck cancers are among the most prevalent cancers of the body. In India, these cancers account for about $50 \%$ of the body's cancers [5]. In the United States, from 1983 to 1987, the prevalence of oral and pharyngeal cancers rose from 3 per 100,000 to 11 , and men were reported to be three times more likely to develop such cancers than women [5,19].

A study by Taziki., et al. in 2019 in Golestan province suggested that the trend of this cancer was on the rise [20].

Development of head and neck cancer causes many challenges to patients, including coping with the initial news of the disease, planning and recovery after surgery, combined therapies, addressing the treatment side effects, social problems, and recuperating from the disease or its recurrence and an expectation of death in advanced cases of the disease [21-23]. On the other hand, because this cancer grows in an area of the body that can be seen by other 


\begin{tabular}{|c|c|c|c|c|c|c|c|c|c|c|}
\hline \multirow{2}{*}{\multicolumn{2}{|c|}{ Demographic variable }} & \multicolumn{2}{|c|}{ Coping } & \multicolumn{2}{|c|}{ Positive focus } & \multicolumn{2}{|c|}{ Planning } & \multicolumn{2}{|c|}{ Deviated thinking } & \multirow{3}{*}{$\begin{array}{c}\text { P-value } \\
0.184\end{array}$} \\
\hline & & \multirow{2}{*}{$\begin{array}{c}\text { Mean } \\
7.06 \\
\end{array}$} & \multirow{2}{*}{$\begin{array}{c}\text { SD } \\
2.78 \\
\end{array}$} & \multirow{2}{*}{$\begin{array}{c}\text { Mean } \\
5.48 \\
\end{array}$} & \multirow{2}{*}{$\begin{array}{c}\text { SD } \\
2.17 \\
\end{array}$} & \multirow{2}{*}{\begin{tabular}{|c|} 
Mean \\
4.71 \\
\end{tabular}} & \multirow{2}{*}{\begin{tabular}{|c|} 
SD \\
2.32 \\
\end{tabular}} & \multirow{2}{*}{$\begin{array}{c}\text { Mean } \\
4.89 \\
\end{array}$} & \multirow{2}{*}{$\begin{array}{c}\text { SD } \\
2.26 \\
\end{array}$} & \\
\hline Gender & Male & & & & & & & & & \\
\hline & Female & 7.08 & 2.63 & 4.95 & 3.34 & 5.44 & 1.92 & 5.00 & 2.12 & \\
\hline \multirow[t]{2}{*}{ Marriage status } & Single & 7.33 & 2.94 & 5.23 & 3.56 & 5.30 & 2.15 & 5.28 & 2.25 & \\
\hline & Married & 7.04 & 2.59 & 5.37 & 2.26 & 5.05 & 2.18 & 4.81 & 2.13 & 0.795 \\
\hline \multirow[t]{7}{*}{ Occupation } & Non-academic Student & 6.88 & 2.92 & 5.00 & 2.66 & 4.81 & 2.26 & 4.56 & 2.31 & \multirow[t]{7}{*}{0.551} \\
\hline & Student & 7.00 & 2.49 & 5.45 & 1.99 & 5.77 & 2.20 & 5.82 & 1.76 & \\
\hline & Employee & 7.21 & 2.83 & 5.50 & 4.27 & 5.26 & 2.18 & 5.45 & 2.02 & \\
\hline & Self-employed & 7.29 & 2.99 & 5.53 & 1.91 & 4.68 & 2.25 & 4.82 & 2.08 & \\
\hline & Retired & 6.91 & 2.97 & 5.23 & 2.37 & 4.68 & 2.25 & 4.41 & 2.58 & \\
\hline & housewife & 7.57 & 2.08 & 4.75 & 2.43 & 5.25 & 2.10 & 4.82 & 2.18 & \\
\hline & Unemployed & 3.75 & 1.71 & 4.00 & 1.41 & 5.00 & 1.41 & 3.00 & 2.94 & \\
\hline \multirow[t]{5}{*}{ Education level } & High school & 7.27 & 2.55 & 5.27 & 1.91 & 5.19 & 2.15 & 4.35 & 2.21 & \multirow{5}{*}{0.991} \\
\hline & Diploma & 7.38 & 2.89 & 5.58 & 2.43 & 4.55 & 2.23 & 5.03 & 2.24 & \\
\hline & Associate's & 7.07 & 2.60 & 5.43 & 1.96 & 5.53 & 2.05 & 5.20 & 2.12 & \\
\hline & Bachelor's & 7.00 & 2.72 & 5.19 & 3.70 & 5.24 & 2.22 & 5.28 & 2.15 & \\
\hline & Master's & 6.86 & 3.29 & 4.71 & 2.06 & 4.86 & 2.04 & 4.57 & 2.23 & \\
\hline \multirow[t]{4}{*}{ Average income } & $<80$ dollars & 6.44 & 2.60 & 5.03 & 2.14 & 4.86 & 2.03 & 4.08 & 2.10 & \multirow{4}{*}{0.031} \\
\hline & 80 - 150 dollars & 7.55 & 2.4 & 5.87 & 2.19 & 5.21 & 2.26 & 5.53 & 2.39 & \\
\hline & 150 - 350 dollars & 7.00 & 2.62 & 4.88 & 3.93 & 4.98 & 1.98 & 4.73 & 1.82 & \\
\hline & Over 350 dollars & 7.57 & 3.17 & 5.43 & 2.64 & 5.19 & 2.77 & 4.86 & 2.41 & \\
\hline \multirow{4}{*}{$\begin{array}{l}\text { Living with/with- } \\
\text { out others }\end{array}$} & With his wife & 6.85 & 2.56 & 5.13 & 2.28 & 4.88 & 2.11 & 4.76 & 2.14 & \multirow{4}{*}{0.241} \\
\hline & Together with parents & 7.10 & 2.80 & 4.52 & 4.55 & 4.97 & 1.96 & 5.61 & 2.19 & \\
\hline & With friends & 6.50 & 2.46 & 5.90 & 1.52 & 5.50 & 2.37 & 4.20 & 1.55 & \\
\hline & Single & 7.87 & 3.40 & 5.91 & 1.95 & 5.65 & 2.52 & 5.09 & 2.54 & \\
\hline \multirow[t]{3}{*}{ Type of treatment } & Chemotherapy & 6.92 & 2.82 & 4.90 & 3.53 & 5.01 & 2.31 & 4.93 & 2.19 & \multirow[t]{3}{*}{0.321} \\
\hline & Surgery & 7.33 & 2.62 & 5.71 & 1.86 & 5.15 & 1.99 & 5.05 & 2.29 & \\
\hline & Chemotherapy and surgery & 7.20 & 2.78 & 5.20 & 2.48 & 5.09 & 2.27 & 4.80 & 2.17 & \\
\hline
\end{tabular}

Table 4: Relationship between demographic variables and duration of and type of treatment with subscales of coping, positive focus, planning, deviated thinking.

$* \mathrm{P}<0.05$ is significant.

people, it can cause beauty, speech and eating problems, thereby affecting family, social aspects, quality of life and beauty [24-26].

Those cancer patients who are not resistant to stress get frustrated, become unable to focus on problems, and cannot make the right decisions, they do not have a plan for the right lifestyle, are pessimistic about their lives, have no control over their own destiny, and do not play an active role in how to form their own lives. Their feedback and practical conducts are irrational and are unable to meet the challenges facing their lives. These complications leave such a profound and lasting effect on the patient's psyche that a recollection of bitter memories of the past even after years could cause anxiety for them, affecting their coping abilities [27].

Head and neck cancer and its treatment also affect breathing, swallowing, communication and the appearance, and these are very important issues for therapists during the treatment period as they can affect patients physically, emotionally and socially. Social injuries are one of the most important aspects of these side effects [28]. 
This study was aimed to evaluate coping with cancer in patients with head and neck cancer using the Cancer Coping Questionnaire. The mean coping score of the participants was $12.2 \pm 37.99$. Since the range of this variable can vary from 22 to 88 , one would conclude that peoples' coping styles with head and neck cancer was at a low level. Peoples' coping under chemotherapy was found to be greater than surgery, but it was no different from surgery with chemotherapy. There was no significant relationship between coping, gender, occupation, level of education, and income.

A review of credible sites illustrated that no study had been conducted on cancer coping styles in patients with head and neck cancer and the only study pertained to Goswami., et al. [29] qualitative study in India.

People create coping styles in a variety of ways. Studies have demonstrated that people mostly make use of problem-oriented, emotion-oriented and avoidance strategies for coping styles [30]. Patients with cancer use spiritual strategies, social support, hope, and cognitive reconstruction, change and distancing in order to cope with the disease. Some coping methods are successful in promoting a sense of well-being, and in others, these processes are useful in creating psychological coping. Examining how patients cope with diseases such as cancer is one of the most critical studies conducted across the globe [31,33].

Many people, having been diagnosed with cancer, experience high levels of inability and frustration while coping with this disease in individual and familial lives. To return to their normal lives, these patients need help to cope with the disease and meet their various needs. Lazarus and Folkman (1984) defined coping as continuous cognitive and behavioral efforts to manage specific internal and external desires valued beyond the individual's resources. In regard to the Folkman and Lazarus's theory, a theory of psychological coping with cancer has been proposed. Cancer coping is referred to a set of attitudes and practices a person adopts to survive, create well-being, feel happy and overcome the stresses caused by cancer. And of course, coping with cancer is a process that unfolds over time. This coping is associated with changes in a person's lifestyle that require planning. Murray and Grayer (2002) have considered the cognitive triangle in cancer patients; a triangle, whose one angle is a person's view of cancer diagnosis and the other angles involving disease control and prognosis. For example, if one learns about being diagnosed with a very malignant cancer (the diagnosis angle) and maintains that there is nothing he can do to treat the disease (control of the disease) and feels completely disappointed with the future (negative prognosis), it is quite natural of him/her to be despaired and feel helplessness [19].
The mean coping score was $23.19 \pm 8.12$ in the individual dimension and $14.09 \pm 3.07$ in the interpersonal dimension. In the interpersonal dimension, with a score ranging between 8 and 32, patients received a relatively moderate score, and therefore were under auspices from the family.

One of the significant cases in this regard is social harms these patients may be exposed to as they encounter with nurses and relatives, whose feelings and behavior can greatly affect the acceptance of treatment and their behavior. Research to identify the role and effects ofnurses' behavior and treatment of cancer patients is promising [33].

The Goswami., et al. study [29] demonstrated that patients with head and neck cancer were desperately needing family support as this cancer had a significant impact on their quality of life. Another study by Goswami., et al. [34] on the effect of psychological factors on treating patients with head and neck cancers demonstrated that calming and reassuring these patients was not easy and the patient and his family should cooperate in this connection. This study recommends to take care of patients with head and neck cancer with sufficient knowledge of the disease process and its outcomes and to provide counseling services in the hospital so that patients' needs are met.

Research findings by Tabrizi., et al. [35] suggested that there was a positive and significant relationship between cancer control and perceived social support. Perceived social support was also identified as the strongest factor affecting the rate of cancer in the study. Close communication and social support provided by family, friends, colleagues, and the community were found to be positively associated with improved performance among patients with breast cancer, resulting in better coping with problems, general adjustment, and cognitive and physical achievements.

The Khodapanahi., et al. study demonstrated that included in different types of social support is the family support contributing a major role to encouraging people to meet health goals with their help being the most important part of social support [36].

In a study conducted by Luszczynska., et al. Lack of attachment to the family environment and, in general, disrupted family relationships could cause rising stress and anxiety, followed by reduced mental health; this means inability to cope with the disease. In the meantime, family members can increase their own supportive behaviors to deal with the disease [37]. 
The research done by Moradi., et al. [38] suggested that adequate support for these patients plays an important role in retaining consciousness and cohesiveness, coping and dealing with cancer as it leaves positive effects on quality of life; it makes people experience less stress through strengthening and increasing patients' knowledge. Hence, the enjoyment of support also empowers patients to cope with cancer grief.

The study by Sajjadian., et al. [39] indicated that seeking social support was one of the most important strategies used by patients, which had been used in both stages (by the patients before and after breast cancer treatment).

Seeking social support has been regarded as one of the basic coping strategies as studies have examined it from different angles and that its has been used with a focus on problem solving or on emotion orientation. Other studies have demonstrated that social support is one of the main strategies to deal with such problems as breast cancer [40-42].

A study by Goswami., et al. [29] suggested that patients with oral cancer could suffer from social problems and psychosocial consequences of the disease. Arunachalam., et al. [43] found similar findings, indicating that appearance deformity would leave a deep psychosocial effect on patients, which was consistent with the research by Vidhubala., et al. [44] and Chaturvedi., et al [45].

In another study, Goswami., et al. [34] maintained that understanding the emotional feelings of cancer patients would encourage patients to better cope with their disease, as this finding was in line with the Röing., et al. studies [46], Pinquart., et al. [47] and Ross., et al. studies [48].

This study found that more than half of the patients had suffered from stress or worried about their disease during the past week. In the study by Goswami., et al. [29], two-thirds of the patients treated were going through stress and feeling depressed and anxious. They were excluded from society and could not associate with other people.

Dropkin., et al. [49] and Wu., et al. [50] found similar findings in terms of anxiety and depression in patients with head and neck cancers. Sharp., et al. [51] also maintained that cancer patients suffered from anxiety and depression.

This study indicated that people's income would make a difference in their coping styles with life and as income increases, peo- ple's coping rate increases. Financial insecurity was seen another major concern of patients in the study conducted by Goswami., et al [29].

This issues especially becomes intense when cancer treatments are not covered by insurance or the men as breadwinners in the family are diagnosed with cancer and their income is affected in some way. A study by Goswami., et al. [29] illustrated that the disease and its complications could prevent people from earning a living and their livelihoods and consequently their daily living expenses may be affected harshly.

In their study, Sharp., et al. [51] found that the cost of cancer treatment was very high. In a systematic study of the economic burden of patients with head and neck cancer, Wissinger., et al. [52] showed that the cost of treatment for head and neck cancer was very expensive, which was in line with the Shankarans [53] research.

Chakrabarty., et al. [54] suggested that in low- and middle-income countries where health care costs are paid by daily incomes would pressure the household income levels.

This study showed that an increase in age reduces the rate of personal and interpersonal coping, and increased duration of the disease would increase personal and interpersonal coping.

On the patients with breast cancer, Sajjadian., et al. study [39] revealed that age and duration of the disease had no effect on the degree of coping. In a study by Goswami., et al. [29] the elderly were found to have less coping. One of the reasons for this difference could be difference of gender as well as the type of cancer.

The results of this study indicated that a rise in age reduced planning and deviated thinking in individuals. Moreover, as the duration of the disease increases, the level of coping increases, the study found.

In other studies, distancing from the problem was seen one of the most widely used strategies in cancer patients [55-58].

In a study by Sajjadian., et al. [40], it was difficult for the patient to distance him/herself from the disease at first, but over time and with rational acceptance, the patients were able to use this method more.

The findings demonstrated that there was no significant relationship between coping, gender, marital status and level of education. 
A study by Sajjadian., et al. [40] suggested that demographic factors were not significantly related with coping. Other studies showed that occupation, marital status and education were not significantly correlated with coping in patients with breast cancer $[42,59,60]$.

\section{Conclusion}

This study reaffirmed that coping in people with head and neck cancer was generally low. Also, a low average score was obtained in the personal and interpersonal dimensions. Individuals' incomes may create differences in the extent of their coping, as increasing age reduces planning and deviated thinking in individuals. To sum, as the duration of the disease increases, the amount of coping increases.

\section{Acknowledgment}

This research has been carried out as an approved research project with the support of the Vice Chancellor for Research and Technology of Kerman University of Medical Sciences (Project number: 449/98 from the Research Center for Social Factors Affecting Oral Health).

\section{Bibliography}

1. Simard EP., et al. "International trends in head and neck cancer incidence rates: Differences by country, sex and anatomic site". Oral Oncology 50 (2014): 387-403.

2. Elango JK., et al. "Trends of head and neck cancers in urban and rural India". Asian Pacific Journal of Cancer Prevention 7 (2006): 108.

3. Siegel R., et al. "Cancer statistics". CA: A Cancer Journal for Clinicians 63 (2013): 11-30.

4. Jayaraj R., et al. "Trends in Incidence of Head and Neck Cancer in the Northern Territory, Australia, between 2007 and 2010". Asian Pacific Journal of Cancer Prevention 15 (2014): 7753.

5. Douglas E., et al. "Non surgical management of head and neck cancers patients". Dental Clinics of North America 38 (1994): 425-445.

6. Wood NK and Goaz PW. "Differential diagnosis of oral and maxillofacial lesions". 5th edition, Mosby Com (1997): 587-593.

7. Lewelyn J and Mitchell R. "Smoking, alcohol and oral cancer in south east Scotland: a 10 years Experience". Journal of the British Association of Oral and Maxillofacial Surgeons 32 (1998): 146-152.
8. Richard CK., et al. "Oral squamous cell carcinoma: new insights". Oral Surgery, Oral Medicine, Oral Pathology 63 (1997): 517-525.

9. Tesseroli de Siqueira JT., et al. "Pain complaint as the first symptom of oral cancer: A descriptive study". Oral Surgery, Oral Medicine, Oral Pathology, and Oral Radiology 102 (2006): 56-61.

10. Vidhubala E., et al. "Coping preferences of head and neck cancer patients - Indian context”. Indian Journal of Cancer 43 (2006): 6-11.

11. Arunachalam D., et al. "Quality of life in cancer patients with disfigurement due to cancer and its treatments". Indian Journal of Palliative Care 17 (2011): 184-190.

12. Koopman $\mathrm{CH}$., et al. "Distress, coping, and social support among rural women recently diagnosed with primary breast cancer". The Breast Journal 1 (2001): 25-33.

13. Kneier A., et al. "Cancer coping strategies.

14. Kyngas H., et al. "Coping with the onset of cancer: coping strategies and resources of young people with cancer". European Journal of Cancer Care 10 (2000): 6-11.

15. Hack TF and Degner LF. "Coping responses following breast cancer diagnosis predict psychological adjustment three years later". Psychooncology 13 (2004): 235-247.

16. Piko B. "Gender differences and similarities in adolescents' ways of coping". The Psychological Record 51 (2001): 223-235.

17. Atef-Vahid MK., et al. "Quality of life, religious attitude and cancer coping in a sample of Iranian patients with cancer". Journal of Research in Medical Sciences 1 (2011): 928-937.

18. Gerami H., et al. "A Report of relative frequency of head and neck tumors and respective factors in Guilan province". Journal of Guilan University of Medical Sciences 24.93 (2015): 1-9.

19. Al-Azri M., et al. "Coping with a diagnosis of breast cancer literature review and implications for developing countries". The Breast Journal 15 (2009): 615-622.

20. Taziki MH., et al. "Epidemiology of head and neck cancers in northern Iran: a 10-year trend study from Golestan province". Archives of Iranian Medicine 21 (2018): 406-411. 
21. Gellrich NC., et al. "Oral cancer malnutrition impacts weight and quality of life". Nutrients 7 (2015): 2145-2160.

22. Dropkin MJ. "Anxiety, coping strategies, and coping behaviors in patients undergoing head and neck cancer surgery". Cancer Nursing 24 (2001): 143-148.

23. Wu YS., et al. "Anxiety and depression in patients with head and neck cancer: 6-month follow-up study". Neuropsychiatric Disease and Treatmen 12 (2016): 1029-1036.

24. Indian Council of Medical Research. Consolidated report of hospital based cancer registries an assessment of the burden and care of cancer patients 14 (2012): 2013.

25. Wissinger E., et al. "The economic burden of head and neck cancer: A systematic literature review". Pharmacoecon 32 (2014): 865-882.

26. Shankaran V. "The Financial impact of cancer care: Implications and potential solutions". The American Journal of Managed Care 21 (2015): SP547-SP550.

27. Chakrabarty J., et al. "Economic burden of cancer in India". Indian Journal of Public Health Research and Development 8 (2017): 137.

28. FDA Approval for Docetaxel - National Cancer Institute (2014).

29. Goswami S and Gupta SS. "How patients of oral cancer cope up with impact of the disease? A qualitative study in central India". Indian Journal of Palliative Care 25 (2019): 103-109.

30. Lazarus RS. "Coping theory and research: past, present, and future”. Psychomatic Medicine 55 (1993): 234-247.

31. Boehmke MM and Dickerson SS. "The diagnosis of breast cancer. Transition from health to illness". Oncology Nursing Forum 33 (2006): 1121-1127.

32. Al-Azri M., et al. "Coping with a diagnosis of breast cancer literature review and implications for developing countries". The Breast Journal 15 (2009): 615-622.

33. Cuffari L., et al. "Pain complaint as the first symptom of oral cancer: A descriptive study". Oral Surgery, Oral Medicine, Oral Pathology, and Oral Radiology 102 (2006): 56-61.
34. Goswami S., et al. "Understanding the psychosocial impact of oral cancer on the family caregivers and their coping up mechanism: a qualitative study in rural wardha, centralindia". Indian Journal of Palliative Care 25 (2019): 421-427.

35. Moghaddam Tabrizi F., et al. "The Investigation of the Relationship Between Cancer Coping and Symptom Management SelfEfficacy, Perceived Social Support, Uncertainty and Life Orientation in Breast Cancer Female Survivors". Scientific Journal of Hamadan Nursing and Midwifery Faculty 26 (2018): 1-10.

36. Khodapanahi MK., et al. "Preparing and investigating the reliability and validation of the family social support questionnaire (FSSQ)". Journal Family Research 5 (2010): 423-439.

37. Luszczynska A., et al. "Self-efficacy and social support predict benefit finding 12 months after cancer surgery: The mediating role of coping strategies". Psychology, Health and Medicine 10 (2005): 365-375.

38. Moradi N AF., et al. "Effects of husband's education on meting supportive care needs of breast cancer patients: A clinical trial". Scientific Journal of Hamadan Nursing and Midwifery Faculty 21 (20113): 40-50.

39. Sajadian A., et al. "Post diagnosis coping strategies patients with breast cancer". International Journal of Behavioral Development 4 (2011): 52-58.

40. Boehmke MM and Dickerson SS. "The diagnosis of breast cancer. Transition from health to illness". Oncology Nursing Forum 33 (2006): 1121-1127.

41. Tan M. "Social support and coping in Turkish patients with cancer". Cancer Nursing 30 (2007): 498-504.

42. Dregeset $\mathrm{S}$ and Lindstrom T. "Coping with a possible breast cancer diagnosis; demographic factors and social support". Journal of Advanced Nursing 3 (2005): 217-226.

43. Vidhubala E., et al. "Coping preferences of head and neck cancer patients - Indian context". Indian Journal of Cancer 43 (2006): 6-11.

44. Arunachalam D., et al. "Quality of life in cancer patients with disfigurement due to cancer and its treatments". Indian Journal of Palliative Care 17 (2011): 184-190. 
45. Chaturvedi SK., et al. "Concerns, coping and quality of life in head and neck cancer patients". Support Care Cancer 4 (1996): 186-190.

46. R?ing M., et al. "Living in a state of suspension - A phenomenological approach to the spouse's experience of oral cancer". Scandinavian Journal of Caring Sciences 22 (2008): 40-47.

47. Pinquart M and S?rensen S. "Correlates of physical health of informal caregivers: A meta-analysis". Gerontology, Series B: Psychological Sciences and Social Sciences 62 (2007): 126-137.

48. Ross S., et al. "Psychosocial adjustment of family caregivers of head and neck cancer survivors". Support Care Cancer 18 (2010): 171-178.

49. Dropkin MJ. "Anxiety, coping strategies, and coping behaviors in patients undergoing head and neck cancer surgery". Cancer Nursing 24 (2001): 143-148.

50. Wu YS., et al. "Anxiety and depression in patients with head and neck cancer: 6-month follow-up study". Neuropsychiatric Disease and Treatment 12 (2016): 1029-1036.

51. Sharp L and Timmons A. "The Financial Impact of a Cancer Diagnosis (2010).

52. Wissinger E., et al. "The economic burden of head and neck cancer: A systematic literature review". Pharmacoeco 32 (2014): 865-882.

53. Shankaran V. "The Financial impact of cancer care: Implications and potential solutions". The American Journal of Managed Care 21 (2015): SP547-SP550.

54. Chakrabarty J., et al. "Economic burden of cancer in India". Indian Journal of Public Health Research and Development 8 (2017): 137.

55. Vargen OM and Bertero CM. "Living with breast cancer". Cancer Nursing 30 (2007): 417-478.

56. Danhauauer SC., et al. "A longitudinal investigation of coping strategies and quality of life among younger women with breast cancer". Cancer 32 (2009): 371-379.

57. Lauver DR., et al. "Stressors and coping strategies among female cancer survivors after Treatments". Cancer Nursing 30 (2007): 101-111.
58. Lambert VA. “Coping strategies and predictors of general wellbeing in women with breast cancer in the people's Republic of china". Nursing and Health Sciences 9 (2007): 199-204.

59. Al-Azri M., et al. "Coping with a diagnosis of breast cancerliterature review and implications for developing countries". The Breast Journal 15 (2009): 615-622.

60. Moor JS., et al. "The Role of Socio-economic Status in Adjustment After Ductal Carcinoma In Situ". Cancer 116 (2010): 1218-1225.

\section{Volume 5 Issue 6 June 2021}

(c) All rights are reserved by Maryam Alsadat

Hashemipour., et al. 